\section{THU0239 OROPHARYNGEAL DYSFUNCTION IN SYSTEMIC SCLEROSIS}

${ }^{1} \mathrm{~F}$ Cozzi, ${ }^{2} \mathrm{~F}$ Pomerri, ${ }^{1} \mathrm{~N}$ Durigon, ${ }^{1} \mathrm{~A}$ Bullo, ${ }^{1} \mathrm{~L}$ Semerano, ${ }^{1} \mathrm{P}$ Sfriso, ${ }^{1} \mathrm{~S}$ Todesco. ${ }^{1}$ Division of Rheumatology; ${ }^{2}$ Institute of Radiology, Padova University, Padova, Italy

\subsection{6/annrheumdis-2001.771}

Background Esophagopathy is one of the most frequent visceral organ involvements in Systemic Sclerosis (SSc). Fibrous tissue substitution of the visceral wall progressively compromises peristalsis and leads to lower oesophageal sphincter incompetence, with dysphagia and reflux esophagitis. The process most frequently involves the lower two thirds of the oesophagus, but in many patients, oropharynx and the upper third of the oesophagus can be involved as well.

Objectives In order to evaluate this aspect of the disease, we submitted a group of sclerodermic patients to videofluorography with contrast agent, a technique that allows to study the oropharyngeal phase of deglutition.

Methods We evaluated 36 SSc patients, 33 female, 3 male, mean age 52 yrs. (range 27-75), mean disease duration 8.5 yrs., 23 with limited SSc, 13 with diffuse SSc. They underwent videofluorography with barium sulphate, which allows to study either the oropharyngeal or the oesophageal phase of deglutition.

Results In 31 patients $(86.1 \%)$ we detected radiographic abnormalities, in $11(30.6 \%)$ of both phases, in $16(44.4 \%)$ of the esophageal phase only, in $4(11.1 \%)$ of the oropharingeal phase only. The oropharyngeal abnormalities, detected in 15(41.7\%) patients, comprised: incompetence of palatoglossus histmus and palatopharyngeus histmus, stasis of the contrast agent in the valleculae and pyriform recesses, and its penetration inside laryngeal haditus.

Conclusion Our study demonstrates that in many SSc patients, even the first phase of deglutition, the oropharyngeal one, is altered. Tissue fibrosis involves even oropharyngeal structures, compromising deglutition in the first phase with higher risk of $a b$ ingestis phenomena.

\section{Epidemiology of rheumatic diseases}

\section{AB0224 INCIDENCE AND PREVALENCE OF RHEUMATIC CONDITIONS IN SOUTHERN EUROPE.(HALKIDIKI STUDY)}

EP Roussou. Rheumatology, Panagia Hospital of B' IKA, Thessaloniki, Greece

\subsection{6/annrheumdis-2001.772}

Background Halkidiki is a region/prefecture of 106.000 inhabitants mostly suburban and rural which attracts approximately 1 million visitors during summer months of June, July, August and September. There is a district hospital, 5 health centres an Orthopaedic unit based at the hospital and 3 Orthopaedic doctors practising privately in addition to the single Rheumatologist practising in the area.

Objectives In order to assess incidence and prevalence of rheumatic conditions in rural and suburban East Meditterannean basin of Southern Europe, medical notes were analysed from a total number of 226 patients who presented themselves to a single Rheumatologist practising in the prefecture of Halkidiki within 3 years from September 1997 to September 2000.

Methods Medical cases were excluded as well as patients visiting the region temporarily. Rheumatology in the region is practised in the community and patients were either self referred or other specialist's referrals. From the 226 patients there were 56 males and 170 females $(\mathrm{m}: \mathrm{f}=1: 3$ ). Their median age was 56.3 (range 11-84).

Results Seventy seven patients out of 226 (34\%) had autoimmune conditions. From these 30 patients had RA of whom 18 patients were newly diagnosed. Forty four patients (19.4\%) had OA, 17 patients $(7.5 \%)$ had spine complains (sciatica, cervical spondylosis, scoliosis) 22 patients $(9.7 \%)$ upper limp [frozen shoulder $(\mathrm{n}=9)$, carpal tunnel $(\mathrm{n}=8)$, flexor tendon nodule $(\mathrm{n}$ $=3)$, epicondylitis $(n=2)]$ and 5 patients $(2.2 \%)$ had lower limp complaints (calcaneal spur, trochanderic bursitis). Twenty two patients (9.7\%) had seronegative arthritis (Ankylosing Spondylitis $\mathrm{n}=5$, Psoriatic Arthritis $\mathrm{n}=13$, Reactive Arthritis $\mathrm{n}=$ 3 , Ulcerative colitis $n=2$ ). Twenty four patients $(10.6 \%)$ had thyroid related disorders, 14 patients $(6.1 \%)$ osteoporosis, 12 patients $(5.3 \%)$ had gout and 5 patients $(2.2 \%)$ had liver disease related arthralgia. Two cases were undiagnosed.

Conclusion Most cases presented to a Rheumatologist in Southern Europe are of degenerative origin or soft tissue rheumatism complaints. Many specialities look after these patients particularly orthopaedics. Rheumatoid Arthritis revealed an incidence of 6/100.000 per year. Psoriatic Arthritis showed an incidence of 3.5/100.000 per year. Polymyalgia Rheumatica/Temporal arteritis showed incidence of $4 / 100.000$ per year being second common autoimmune disease after RA. Finally thyroid related (autoimmune or functional) arthralgia is found quite common in the region being third among muskuloskeletal disorders after OA and RA.

\section{AB0225 PREVALENCE OF RHEUMATIC DISEASES IN GENERAL MEDICINE PRACTICE IN PORTUGAL}

${ }^{1} \mathrm{PJ}$ Clemente-Coelho, ${ }^{2} \mathrm{ML}$ Marques-Matos. ${ }^{1}$ Rheumatology Service-Instituto Português de Reumatologia; ${ }^{2}$ Centro de Saúde Da Alameda, ARS de Lisboa E Vale Do Tejo, Lisboa Codex, Portugal

10.1136/annrheumdis-2001.773

Background Rheumatic Diseases are of the most important causes of morbidity in our society, with high social and economic repercussion.

Objectives To study the prevalence of rheumatic diseases in general practise and their implications related to chronic use of medication and work absenteeism.

Methods Prospective study with observance of the consecutive patients in a general practitioner appointment during a period of six months.

Results 1219 appointments corresponding to 591 patients were analysed. Rheumatic complaints were the most prevalent motive of appointment (21\%) followed by cardiovascular diseases $(14,7 \%)$ and psychiatric diseases $(12,2 \%)$. The most frequent rheumatic diseases were soft-tissue rheumatism, including lowback pain and other vertebral pain $(48,5 \%)$ and osteoarthritis $(18,1 \%)$. Rheumatic diseases were the third cause of chronic use of medication, after psychiatric diseases and gastric-intestinal diseases. Rheumatic diseases were the first cause of work absenteeism with a total of $42,5 \%$ od days lost in work in the active patients group. Among the rheumatic diseases, low-back pain and osteoarthritis were the main causes of work absenteeism, but rheumatoid arthritis was the disease of higher level of individual morbidity. 